\title{
Untreated early childhood caries: the role of parental eating behavior
}

\author{
Maria Dalla COSTA ${ }^{(a)}$ \\ Vanessa da Rocha CHAPANSKI(b) \\ Aline Fabris de Araujo CREMA(a) \\ Bruna Letícia Vessoni \\ MENONCIN(a) iD \\ Doroteia Aparecida \\ HÖFELMANN(c) iD \\ Fabian Calixto FRAIZ(a) iD \\ (a) Universidade Federal do Paraná - UFPR, \\ Department of Stomatology, Curitiba, \\ PR, Brazil. \\ (b) Universidade Federal do Paraná - UFPR, \\ Department of Community Health, Curitiba, \\ PR, Brazil. \\ (c) Universidade Federal do Paraná - UFPR, \\ Department of Nutrition, Curitiba, \\ PR, Brazil.
}

Declaration of Interests: The authors certify that they have no commercial or associative interest that represents a conflict of interest in connection with the manuscript.

\section{Corresponding Author:}

Fabian Calixto Fraiz

E-mail: fabianfraiz@gmail.com

https://doi.org/10.1590/1807-3107bor-2022.vol36.0010

Submitted: February 9, 2021

Accepted for publication: August 31, 2021

Last revision: October 7, 2021
Abstract: The aim of the present study was to analyze the association between parental eating behavior and untreated early childhood caries (ECC). A cross-sectional study was conducted with a representative sample of 432 parent-child dyads with children aged 18 to 36 months, at Municipal Child Education Centers in São José dos Pinhais, Brazil. The parents answered a questionnaire addressing demographic and socioeconomic characteristics, and the children were examined for dental caries (modified dmft index) by a single examiner (kappa $=0.80)$. A six-item questionnaire was administered addressing parental food consumption, parental control of the child's food consumption, and parental offering of foods to the child. Three items were considered indicative of positive behavior, and three, of negative behavior. Univariate and multivariate Poisson regression analyses with robust variance were used for the data analysis $(\alpha=0.05)$. The prevalence of untreated ECC was $20.3 \%$ (95\%CI: 16.7-24.4). In the multiple regression model adjusted for the child's age and the parent's schooling, negative parental behavior was associated with a greater frequency of untreated ECC $\left(\mathrm{PR}_{\mathrm{a}}=1.213\right.$; 95\%CI:1.032-1.427, $\mathrm{p}=0.019)$, but lost its significance when adjusted by positive parental behavior $\left(\mathrm{PR}_{\mathrm{a}}=1.156\right.$; 95\%CI: 0.983-1.358, $\left.\mathrm{p}=0.079\right)$. Based on the present findings, positive parental eating behaviors are capable of minimizing the impact of negative parental behaviors on the prevalence of untreated early childhood caries.

Keywords: Dental Caries; Parenting; Feeding Behavior; Child, Preschool.

\section{Introduction}

Dental caries continues to be a challenge to public health. This highly prevalent disease exerts an impact on the quality of life of children and their families, and generates substantial costs. ${ }^{1,2}$ The literature clearly indicates that sugar intake is the main factor associated with the development of caries. ${ }^{3,4}$ However, reducing this intake continues to pose a major challenge to families.

Studies have indicated that parental factors are predictors of healthy behavior in children, such as the habit of brushing one's teeth, ${ }^{5}$ and the adoption of healthy eating practices. ${ }^{6}$ The models set by, the attitudes shown by, and the foods offered by the family contribute to defining the eating behavior of children. ${ }^{6,7,8}$ Indeed, the home environment is capable of encouraging both healthy and unhealthy eating behaviors 
in children. ${ }^{9,10}$ When parents offer adequate foods to their child, befitting the child's age, in a calm setting, and accompanied by responsive vigilance, they promote conscious consumption in children, and facilitate the development of self-control and responsible eating behavior. ${ }^{11}$

Inappropriate parental behavior during meals, marked by parents' consuming and offering the child inadequate foods, is associated with the development of dental caries. ${ }^{12,13}$ However, the same family may adopt both positive and negative behaviors in regard to diet; this suggests that the multiple nuances of parental behavior should be studied to gain a better understanding of how this behavior influences the occurrence of dental caries in children.

Early childhood merits special attention in this regard, since the eating habits adopted in this phase are predictors of future practices. Therefore, the aim of the present study was to analyze the association between parental eating behavior (positive and negative aspects) and dental caries experience in early childhood.

\section{Methodology}

This study received approval from the institutional review board of the Health Sciences Department of the Federal University of Paraná (certificate number: 2.033.588, dated 26 April 2017), and was conducted according to the STROBE Statement.

A cross-sectional study was conducted with a representative sample of preschool children aged 18 months to 35 months and 29 days enrolled full-time at the Municipal Child Education Centers in the city of São José dos Pinhais, in southern Brazil. The sample size was calculated using the formula for proportion with a finite population to gather a sufficient number of individuals to compose the group being researched. In early 2017, 2667 children between 18 and 36 months of age were enrolled in the public child education system in the city of São José dos Pinhais. This research was part of a larger study with several outcomes, for which a more conservative calculation was adopted, with an outcome prevalence of $50 \%$ to maximize the sample size. A minimum sample of 404 children was determined, to which
$30 \%$ was added to compensate for possible dropouts, leading to a sample of 526 children, considering a 95\% confidence level, a $5 \%$ precision for estimates, and a 1.2 design effect to compensate for cluster sampling.

Random sampling was performed in two stages: educational units and children. In 2017, the city had 43 Child Education Centers, 20 of which were randomly selected to ensure the representativeness of the sample. Moreover, proportional distribution was adopted to ensure the representativeness of students between 18 and 36 months of age enrolled at each Child Education Center. The children were randomly selected after the schools were defined, to enable each child the same chance of being included in the study. If a selected child was not present, or did not meet the inclusion criteria, another child was selected at random.

The inclusion criteria comprised children aged 18 to 35 months and 29 days, of either sex, enrolled at the Child Education Center, and a statement of informed consent duly signed by a legal guardian. The exclusion criterion was children with a systemic condition, such as a syndrome, cerebral palsy or other condition that impeded clinical examination or comparisons of nutritional status and eating habits, because of special needs (based on information provided by the parents/guardians).

Prior to the study, the researcher in charge of the data collection underwent training exercises (theory and analysis of clinical images for seven hours). Calibration was performed through clinical examinations at the pediatric dental clinic of the university, under the supervision of a researcher experienced in epidemiological studies, who served as the "gold standard." This step involved the participation of 15 children who met the same inclusion criteria as those in the main study. Individual protective equipment was used to control cross-infection. Sterilized gauze was used to clean and dry the tooth surfaces. The first clinical examination was performed to determine the interexaminer agreement using the kappa statistic. After seven days, the same children were examined a second time to determine intraexaminer agreement. Kappa coefficients for dental caries were determined on a tooth-by-tooth basis, and were $\geq 0.80$ for both interexaminer and intraexaminer agreement. 
A pilot study was then conducted at a Child Education Center in a city that was not included in the main study. Fifty-five questionnaires and statements of informed consent were sent to families selected by convenience to test the understanding of the data collection forms. On the day of the collection, 22 children took part in the clinical examinations. Adjustments based on the pilot study were made in the order and graphic formatting of the questions, to facilitate the respondents' understanding.

A self-administered questionnaire was created to collect information on demographic and socioeconomic characteristics for the main study, such as family income, and number of residents in the home, as well as characteristics of the guardians (marital status, schooling and employment status) and the children (sex and age). Parental eating behavior was also evaluated on the questionnaire using six questions - three considered indicative of positive behavior, and three, of negative behavior. These questions were developed based on the model proposed by the Parent Mealtime Action Scale (PMAS) ${ }_{1}^{14}$ which has been translated and validated for Portuguese. ${ }^{15}$ The scored response options were "never," "sometimes," and "always," (with weights of 1, 2 and 3, respectively), and considered parental behavior in a typical week. The three questions on positive behavior were related to parental consumption (Do you eat vegetables every day?), parental control of the child's consumption (Do you restrict your child from eating too much every day?), and the offering of healthy foods (Do you offer your child vegetables every day?). Higher scores given to these questions denoted more positive behavior. The three questions on negative behavior were related to parental consumption (Do you have sweetened soft drinks every day?), parental control of the child's consumption (Do you let your child eat whatever he/she wants every day?), and the offer of unhealthy foods (Do you offer your child sweetened beverages or foods in his/her feeding bottle every day?). Higher scores on these questions denoted more negative behavior.

After the signed statement of informed consent was received, and the questionnaire was completed, the clinical examinations of the children were performed to collect data on caries at the Child Education
Centers. The assessment was conducted following the criteria of the World Health Organization ${ }^{16}$, using the modified decayed, missing and filled teeth (dmft) index, ${ }^{17}$ which includes non-cavitated white spots. The examinations were performed under natural light with the child in a supine position, using sterilized WHO probes and flat mouth mirrors. The examiner used individual protective equipment to guard against cross-infection. Sterile gauze was used to clean and dry the dental surfaces, when needed.

Statistical analysis was performed with the SPSS software program (IBM. Released 2017. IBM SPSS Statistics for Windows, Version 25.0. Armonk, NY: IBM). The response variable (untreated ECC) was dichotomized as "present" (when the $d$ component of the $\mathrm{dmft}$ index was marked, or a white spot was detected), or "absent" (when no teeth had cavitated carious lesions or white spots).

The independent variables were categorized as follows: guardian's schooling $(<11$ years of formal study; $\geq 11$ years of formal study), guardian's marital status (married/common-law relationship [living together for $\geq$ five years]; separated/widowed), guardian's place of work (at home; outside the home with signed working papers; outside the home without working papers), child's sex (female; male) and child's age (in months). Household income per capita was dichotomized by the median as $<\mathrm{R} \$ 500$ or $\geq \mathrm{R} \$ 500$. Parental behavior was considered a numerical value ranging from 1 to 3 .

Associations between the response variable (untreated ECC) and other variables were tested using univariate Poisson analysis with robust variance. Variables with a p-value $<0.25$ in the univariate analysis were incorporated into the multiple Poisson regression model with robust variance. Income was not included in the model because this item frequently went unanswered in the questionnaire. Variables that enabled the best adjustment, and those that remained significant were maintained in the final model. The significance level was set at $5 \%$ for all analyses.

\section{Results}

A total of 526 statements of informed consent were distributed. Two children were excluded due to 
allergy to cow milk protein (reported by the parents); eight were excluded for changing to another Child Education Center, or being absent on the day scheduled for the clinical examination; 16 refused to undergo the clinical examination; and the questionnaire was not returned in 68 cases. Thus, the sample consisted of 432 children (response rate: $82.1 \%$ ). The mean age of the children was 29 months (standard deviation [SD]: 4.7), and boys accounted for $57.2 \%$ of the sample.

The demographic and socioeconomic variables are displayed in Table 1. Most of the parents/guardians

Table 1. Demographic and socioeconomic characteristics of guardians of preschool children. São José dos Pinhais, PR, Brazil ( $\mathrm{n}=432$ ).

\begin{tabular}{lcc}
\hline Variable & $\mathrm{n}$ & $\%$ \\
\hline $\begin{array}{l}\text { Conjugal status } \\
\text { Common law marriage }\end{array}$ & 307 & 69.9 \\
$\quad \begin{array}{l}\text { Non-common-law marriage } \\
\text { Schooling }\end{array}$ & 121 & 27.6 \\
$\quad<11$ years & 310 & 73.1 \\
$\geq 11$ years & 114 & 26.9 \\
Employment status & & \\
$\quad$ Works from home & 104 & 24.5 \\
$\quad$ Works outside the home with signed work papers & 217 & 51.1 \\
\hline Works outside the home without work papers & 104 & 24.5 \\
\hline
\end{tabular}

Values lower than 432 are due to missing data for the variable.
(73.1\%) had less than 11 years of schooling (corresponding to an incomplete high school education), and were in a common-law marriage relationship (69.9\%). The majority of the families were economically active, with formal employment and signed working papers (51.1\%). Mean household income per capita was $\mathrm{R} \$ 574.26(\mathrm{SD}=\mathrm{R} \$ 386.22)$, and the median was $\mathrm{R} \$ 500$ (range: $\mathrm{R} \$ 16.70$ to 2,500.00).

The prevalence of untreated ECC was $20.3 \%$ (95\%CI: 16.7-24.4). No associations were found between untreated ECC and the child's sex or household income per capita. The prevalence of untreated ECC was higher among children whose parents/guardians had less schooling, compared to those whose parents had more schooling $(p=0.040)$. The mean age of the children with untreated ECC was 30.9 months $(\mathrm{SD}=0.43)$, and a median of 30 months (range: 19 to 35 months). Children without caries were younger, with a mean of 28.7 months $(S D=0.26)$, and a median of 29 months (range: 18 to 35 months) (Mann Whitney; $\mathrm{p}=0.008)$ (Table 2).

Negative parental behavior was associated with a greater frequency of untreated $\mathrm{ECC}\left(\mathrm{PR}_{\mathrm{a}}=1.213\right.$; $95 \% \mathrm{CI}: 1.032-1.427, \mathrm{p}=0.019)$. However, the association with negative behavior lost its significance when adjusted by positive behavior $\left(\mathrm{PR}_{\mathrm{a}}=1.156 ; 95 \% \mathrm{CI}\right.$ : $0.983-1.358, \mathrm{p}=0.079$ ) (Table 3).

Table 2. Univariate poisson analysis with robust variance of association between socioeconomic variables and prevalence of untreated dental caries in preschool children. São José dos Pinhais, PR, Brazil ( $n=432)$.

\begin{tabular}{|c|c|c|c|c|c|c|}
\hline \multirow{3}{*}{ Variable } & \multicolumn{5}{|c|}{ Untreated caries } & \multirow{3}{*}{$95 \% \mathrm{Cl}$} \\
\hline & Yes & No & \multirow{2}{*}{ Total } & \multirow{2}{*}{$p$-value } & \multirow{2}{*}{$\mathrm{PR}_{c}$} & \\
\hline & n (\%) & n (\%) & & & & \\
\hline \multicolumn{7}{|l|}{ Guardian's schooling } \\
\hline$<11$ years & $70(22.6)$ & $240(77.45)$ & 310 & 0.040 & 1 & \\
\hline$\geq 11$ years & $15(13.20)$ & $99(86.8)$ & 114 & & 0.583 & $0.348-0.975$ \\
\hline \multicolumn{7}{|l|}{ Child's sex } \\
\hline Female & $30(16.2)$ & $155(83.8)$ & 185 & 0.055 & 0.679 & $0.457-1.009$ \\
\hline Male & $59(23.9)$ & $188(76.1)$ & 247 & & 1 & \\
\hline \multicolumn{7}{|c|}{ Household income per capita } \\
\hline$\geq$ Median ( $\$$ \$ 500) & $24(15.2)$ & $134(84.8)$ & 158 & 0.085 & 0.677 & $0.432-1.055$ \\
\hline$<$ Median (R\$ 500) & $47(22.5)$ & $162(77.5)$ & 209 & & 1 & \\
\hline \multicolumn{7}{|l|}{ Child's age (in months) } \\
\hline Mean (SD) & $30.9(0.43)$ & $28.7(0.26)$ & & 0.008 & 1.055 & $1.014-1.097$ \\
\hline Median (min-max) & $30(19-35)$ & $29(18-35)$ & & & & \\
\hline
\end{tabular}

Values lower than 432 are due to missing data for the variable. Significant results at $5 \%$ level in bold;. PRc: crude prevalence ratio; $\mathrm{Cl}$ : confidence interval. 
Table 3. Multiple poisson model with robust variance for untreated dental caries in preschool children. São José dos Pinhais, PR, Brazil ( $\mathrm{n}=432)$.

\begin{tabular}{|c|c|c|c|c|c|c|c|c|c|}
\hline \multirow{2}{*}{$\begin{array}{l}\text { Variable } \\
\text { Parental behavior }\end{array}$} & \multicolumn{3}{|c|}{ Model 1} & \multicolumn{3}{|c|}{ Model 2} & \multicolumn{3}{|c|}{ Model 3} \\
\hline & $\mathrm{PR}_{\mathrm{a}}$ & $95 \% \mathrm{Cl}$ & $p$-value & $\mathrm{PR}_{\mathrm{a}}$ & $95 \% \mathrm{Cl}$ & $p$-value & $\mathrm{PR}_{\mathrm{a}}{ }^{*}$ & $95 \% \mathrm{Cl}$ & $p$-value \\
\hline Positive & - & - & - & 0.887 & $0.756-1.040$ & 0.139 & 0.895 & $0.760-1.054$ & 0.184 \\
\hline Negative & 1.213 & $1.032-1.427$ & 0.019 & - & - & - & 1.156 & $0.983-1.358$ & 0.079 \\
\hline Child's age & 1.051 & $1.006-1.098$ & 0.025 & 1.057 & $1.013-1.103$ & 0.010 & 1.057 & $1.011-1.106$ & 0.015 \\
\hline \multicolumn{10}{|c|}{ Guardian's schooling } \\
\hline $\begin{array}{l}<11 \text { years } \\
\geq 11 \text { years }\end{array}$ & $\begin{array}{c}1 \\
0.713\end{array}$ & $0.423-1.204$ & 0.206 & $\begin{array}{c}1 \\
0.630\end{array}$ & $0.378-1.049$ & 0.076 & $\begin{array}{c}1 \\
0.732\end{array}$ & $0.433-1.237$ & 0.244 \\
\hline
\end{tabular}

Values lower than 432 are due to missing data for the variable. Significant results at $5 \%$ level in bold. PR: adjusted prevalence ratio; $\mathrm{Cl}$ : confidence interval. Model 1: Association between untreated ECC and negative parental behavior adjusted by child's age and guardian's schooling; Model 2: Association between untreated ECC and positive parental behavior adjusted by child's age and guardian's schooling; Model 3: Association between untreated ECC and negative and positive parental behavior adjusted by child's age and guardian's schooling.

\section{Discussion}

The main finding of the present study was that negative parental eating behavior is related to a greater frequency of untreated ECC. However, positive parental behavior is capable of attenuating the impact of negative parental behavior on untreated ECC. This implies that dietary counseling for the prevention of dental caries should include all aspects of a family's eating behavior, since the development of eating practices in children involves a complex interaction of behavioral, biological, environmental, familial and socioeconomic factors. ${ }^{18,19}$ It has been demonstrated that the eating pattern of parents sets an example capable of inducing healthy or unhealthy habits in the eating behavior of children. ${ }^{6}$

The fact that children tend to adopt the eating behavior of their parents has been known for decades. ${ }^{10}$ Behavioral modeling is a process in which beliefs and attitudes are formed based on observing one's parents..$^{20} \mathrm{~A}$ recent systematic review on the modeling of food intake showed that the effects are substantial. ${ }^{21}$ Children create perceptions regarding their parents' food consumption, and reproduce this behavior. ${ }^{10}$ Together with the availability of different foods and the family's eating pattern, parental norms and habits constitute the references for children regarding what is appropriate for consumption. ${ }^{10,22}$ The introduction of new foods is also facilitated by parental eating behavior, since children are more likely to select and consume food that is not yet part of their routine when they see their parents doing so. ${ }^{23}$
Inadequate parental food consumption is associated with a diet that is poor in fruits and vegetables, ${ }^{24,25}$ and with a greater consumption of snacks by children. 14,15,26 It is likely that parents who eat inadequate foods will make such foods available at home; this facilitates the repeated offer of and access to these foods, and influences their acceptance by the child. ${ }^{710}$

Although negative parental eating behavior is related to adverse health conditions in children, such as overweight and childhood obesity, 27,28,29,30 the dental literature correlating parental eating behavior and childhood caries is scarce. A Brazilian study involving 686 five-year-old children and evaluating behavior at meals found that parental eating of sweets was associated with a greater frequency of untreated dental caries in their children. ${ }^{7}$

In contrast, parents who are more conscientious regarding the quality of their diet and that of their children, and who promote alternative foods with reduced fat intake, have children who experience fewer caries. ${ }^{7,10}$ Parental control over children's eating habits also exerts an influence on the prevalence of dental caries. ${ }^{7,13,31}$ Establishing strategies for a diet marked by the consumption of healthy foods is fundamental, since the adoption of these strategies has a potentially positive impact on reducing dental caries among preschool children - even those with a high intake of foods with cariogenic potential. ${ }^{32}$

The present findings should be considered in the context of their limitations. Although the sample planning was designed with concerns for randomization and representativeness, the 
generalization of results should be seen with caution. In addition, this research used a questionnaire specifically designed to address its objectives, and did not presume to develop an instrument to be used in other studies.

Moreover, since a self-administered questionnaire was used, we may presume that there was a certain degree of difficulty in understanding it, based on the level of oral health literacy of the respondents. ${ }^{33}$ As occurs with all questionnaires, it is also possible that the parents opted for more socially acceptable answers. ${ }^{34}$

We are just beginning to understand the complexity of factors that influence child eating behaviors associated with ECC. However, it is fundamental to consider these factors if we hope to ensure the effective implementation of educational measures that promote the adoption of healthy eating practices in early childhood.

\section{Acknowledgments}

The authors are grateful to the Brazilian funding agency, Coordenação de Aperfeiçoamento de Pessoal de Nivel Superior (CAPES [Coordination for the Advancement of Higher Education Personnel], funding code 001), and declare no potential conflicts of interest with respect to the authorship and/or publication of this article.

\section{References}

1. Singh N, Dubey N, Rathore M, Pandey P. Impact of early childhood caries on quality of life: child and parent perspectives. J Oral Biol Craniofac Res. 2020 Apr-Jun;10(2):83-6. https://doi.org/10.1016/j.jobcr.2020.02.006

2. Kassebaum NJ, Bernabé E, Dahiya M, Bhandari B, Murray CJ, Marcenes W. Global burden of untreated caries: a systematic review and metaregression. J Dent Res. 2015 May;94(5):650-8. https://doi.org/10.1177/0022034515573272

3. Avila WM, Pordeus IA, Paiva SM, Martins CC. Breast and bottle feeding as risk factors for dental caries: a systematic review and meta-analysis. PLoS One. 2015 Nov;10(11):e0142922. https://doi.org/10.1371/journal.pone.0142922

4. Chaffee BW, Feldens CA, Rodrigues PH, Vítolo MR. Feeding practices in infancy associated with caries incidence in early childhood. Community Dent Oral Epidemiol. 2015 Aug;43(4):338-48. https://doi.org/10.1111/cdoe.12158

5. Berzinski M, Morawska A, Mitchell AE, Baker S. Parenting and child behaviour as predictors of toothbrushing difficulties in young children. Int J Paediatr Dent. 2020 Jan;30(1):75-84. https://doi.org/10.1111/ipd.12570

6. Scaglioni S, Salvioni M, Galimberti C. Influence of parental attitudes in the development of children eating behaviour. Br J Nutr. 2008 Feb;99(S1 Suppl 1):S22-5. https://doi.org/10.1017/S0007114508892471

7. Bonotto DV, Montes GR, Ferreira FM, Assunção LR, Fraiz FC. Association of parental attitudes at mealtime and snack limits with the prevalence of untreated dental caries among preschool children. Appetite. 2017 Jan;108:450-5. https://doi.org/10.1016/i.appet.2016.11.007

8. Woo Baidal JA, Morel K, Nichols K, Elbel E, Charles N, Goldsmith J, et al. Sugar-sweetened beverage attitudes and consumption during the first 1000 days of life. Am J Public Health. 2018 Dec;108(12):1659-65. https://doi.org/10.2105/AJPH.2018.304691

9. Duijster D, Jong-Lenters M, Ruiter C, Thijssen J, Loveren C, Verrips E. Parental and family-related influences on dental caries in children of Dutch, Moroccan and Turkish origin. Community Dent Oral Epidemiol. 2015 Apr;43(2):152-62. https://doi.org/10.1111/cdoe.12134

10. Larsen JK, Hermans RC, Sleddens EF, Engels RC, Fisher JO, Kremers SP. How parental dietary behavior and food parenting practices affect children's dietary behavior. Interacting sources of influence? Appetite. 2015 Jun;89:246-57. https://doi.org/10.1016/i.appet.2015.02.012

11. Jong-Lenters M, Duijster D, Bruist MA, Thijssen J, Ruiter $C$. The relationship between parenting, family interaction and childhood dental caries: a case-control study. Soc Sci Med. 2014 Sep;116:49-55. https://doi.org/10.1016/j.socscimed.2014.06.031

12. Sujlana A, Pannu PK. Family related factors associated with caries prevalence in the primary dentition of five-year-old children. J Indian Soc Pedod Prev Dent. 2015 Apr-Jun;33(2):83-7. https://doi.org/10.4103/0970-4388.155108

13. Hooley M, Skouteris H, Boganin C, Satur J, Kilpatrick N. Parental influence and the development of dental caries in children aged 0-6 years: a systematic review of the literature. J Dent. 2012 Nov;40(11):873-85. https://doi.org/10.1016/i.jdent.2012.07.013

14. Hendy HM, Williams KE, Camise TS, Eckman N, Hedemann A. The Parent Mealtime Action Scale (PMAS). Development and association with children's diet and weight. Appetite. 2009 Apr;52(2):328-39. https://doi.org/10.1016/i.appet.2008.11.003

15. Petty ML, Escrivão MA, Souza AA. Preliminary validation of the Parent Mealtime Action Scale and its association with food intake in children from São Paulo, Brazil. Appetite. 2013 Mar;62:166-72. https://doi.org/10.1016/j.appet.2012.11.024 
16. World Health Organization. Oral health surveys: basic methods. Geneva: World Health Organization; 2013.

17. Alves LS, Susin C, Damé-Teixeira N, Maltz M. Impact of different detection criteria on caries estimates and risk assessment. Int Dent J. 2018 Jun;68(3):144-51. https://doi.org/10.1111/idj.12352

18. Pimpin L, Ambrosini GL, Llewellyn CH, Johnson L, Jaarsveld CH, Jebb SA, et al. Dietary intake of young twins: nature or nurture? Am J Clin Nutr. 2013 Nov;98(5):1326-34. https://doi.org/10.3945/ajcn.113.065250

19. Liew J, Zhou Z, Perez M, Yoon M, Kim M. Parental child-feeding in the context of child temperament and appetitive traits: evidence for a biopsychosocial process model of appetite self-regulation and weight status. Nutrients. 2020 Oct;12(11):E3353. https://doi.org/10.3390/nul2113353

20. Bandura A. Self-efficacy: toward a unifying theory of behavioral change. Adv Behav Res Ther. 1978;1(4):139-61. https://doi.org/10.1016/0146-6402(78)90002-4

21. Cruwys T, Bevelander KE, Hermans RC. Social modeling of eating: a review of when and why social influence affects food intake and choice. Appetite. 2015 Mar;86:3-18. https://doi.org/10.1016/j.appet.2014.08.035

22. Herman CP, Polivy J. Normative influences on food intake. Physiol Behav. 2005 Dec;86(5):762-72. https://doi.org/10.1016/i.physbeh.2005.08.064

23. Shutts K, Kinzler KD, DeJesus JM. Understanding infants' and children's social learning about foods: previous research and new prospects. Dev Psychol. 2013 Mar;49(3):419-25. https://doi.org/10.1037/a0027551

24. Blissett J. Relationships between parenting style, feeding style and feeding practices and fruit and vegetable consumption in early childhood. Appetite. 2011 Dec;57(3):826-31. https://doi.org/10.1016/j.appet.2011.05.318

25. Rodenburg G, Oenema A, Kremers SP, Mheen D. Parental and child fruit consumption in the context of general parenting, parental education and ethnic background. Appetite. 2012 Feb;58(1):364-72. https://doi.org/10.1016/i.appet.2011.11.001

26. Ventura AK, Worobey J. Early influences on the development of food preferences. Curr Biol. 2013 May;23(9):R401-8. https://doi.org/10.1016/j.cub.2013.02.037

27. Ek A, Sorjonen K, Eli K, Lindberg L, Nyman J, Marcus C, et al. Associations between parental concerns about preschoolers' weight and eating and parental feeding practices: results from analyses of the child eating behavior questionnaire, the child feeding questionnaire, and the lifestyle behavior checklist. PLoS One. 2016 Jan;11(1):e0147257. https://doi.org/10.1371/journal.pone.0147257

28. Nowicka P, Sorjonen K, Pietrobelli A, Flodmark CE, Faith MS. Parental feeding practices and associations with child weight status. Swedish validation of the Child Feeding Questionnaire finds parents of 4-year-olds less restrictive. Appetite. 2014 Oct;81:232-41. https://doi.org/10.1016/i.appet.2014.06.027

29. Saltzman JA, Pineros-Leano M, Liechty JM, Bost KK, Fiese BH. Eating, feeding, and feeling: emotional responsiveness mediates longitudinal associations between maternal binge eating, feeding practices, and child weight. Int J Behav Nutr Phys Act. 2016 Aug;13(1):89. https://doi.org/10.1186/s12966-016-0415-5

30. Souto-Gallardo MC, Bacardí-Gascón M, Benjamin-Neelon S, Jiménez-Cruz A, Pineda-García G. Association of food parenting practices on child BMI z score and waist circumference in mexican preschool children after 1 year of follow-up. J Nutr Educ Behav. 2020 Jan;52(1):73-9. https://doi.org/10.1016/i.jneb.2019.09.014

31. Kirthiga M, Murugan M, Saikia A, Kirubakaran R. Risk factors for early childhood caries: a systematic review and meta-analysis of case control and cohort studies. Pediatr Dent. 2019 Mar;41(2):95-112.

32. Morikava FS, Fraiz FC, Gil GS, de Abreu MH, Ferreira FM. Healthy and cariogenic foods consumption and dental caries: a preschool-based cross-sectional study. Oral Dis. 2018 Oct;24(7):1310-7. https://doi.org/10.1111/odi.12911

33. Firmino RT, Fraiz FC, Montes GR, Paiva SM, Granville-Garcia AF, Ferreira FM. Impact of oral health literacy on self-reported missing data in epidemiological research. Community Dent Oral Epidemiol. 2018 Dec;46(6):624-30. https://doi.org/10.1111/cdoe.12415

34. Fries LR, van der Horst K, Moding KJ, Hughes SO, Johnson SL. Consistency between parent-reported feeding practices and behavioral observation during toddler meals. J Nutr Educ Behav. 2019 Nov - Dec;51(10):1159-67. https://doi.org/10.1016/i.jneb.2019.08.005 